\title{
Relationship between diabetic retinopathy severity and the timespan between the endocrinopathy diagnosis and the first ophthalmic examination
}

\author{
Relação entre a gravidade da retinopatia diabética e o tempo decorrido entre \\ o diagnóstico da endocrinopatia e o primeiro exame oftalmológico
}

\author{
Rony Carlos Preti ${ }^{1}$ \\ Augusto Alves Lopes Motta ${ }^{2}$ \\ Otacílio de O. Maia Júnior ${ }^{3}$ \\ Celso Morita ${ }^{4}$ \\ Vinícius Paganini Nascimento \\ Mário Luiz Ribeiro Monteiro ${ }^{6}$ \\ Walter Yukihiko Takahashi ${ }^{7}$
}

\begin{abstract}
Purpose: To investigate whether the time interval between type 2 diabetes mellitus (DM) diagnosis and the first fundoscopic examination is related with the presence and the severity of diabetic retinopathy (DR) observed. Methods: A survey of 105 type 2 DM patients referred to ophthalmologic evaluation in the "Hospital das Clinicas" (HC), University of São Paulo Medical School (USPMS). Results: Regarding classification of DR in the 105 patients, 15 (14.28\%) did not show signs of DR, and $90(85.72 \%)$ exhibited them on fundoscopy. Sixty patients underwent laser therapy, and $46.66 \%$ reported poor control of DM. Only $15.23 \%$ of DM patients were adequately screened for DR on the first year of their DM diagnosis. Among the 36 patients (34.30\%) examined within five years of DM diagnosis, $58.33 \%$ did not present or demonstrate signs of mild DR and $22.20 \%$ of proliferative DR; 30 patients underwent an ophthalmologic examination after more than eleven years of DM diagnosis, $21.62 \%$ did not exhibit signs of DR and $59.46 \%$ were classified as proliferative DR. Conclusion: This study showed a statistically significant relationship between the time interval from the diagnosis of type $2 \mathrm{DM}$ and the first fundoscopic examination with the severity of DR.
\end{abstract}

Keywords: Diabetes mellitus; Diabetic retinopathy

\section{INTRODUCTION}

Diabetic retinopathy (DR) is the leading cause of visual acuity reduction in the United States ${ }^{(1-2)}$. In Brazil, it has been estimated that half of the patients with DM suffer from DR and $7.5 \%$ of them are unable to work $^{(3)}$. Knowledge of the risk factors that lead to DR and its progression are therefore extremely important for preventing visual $\operatorname{loss}^{(4)}$ and clinical studies have shown that inadequate plasma glucose control is associated with an increase in DR severity ${ }^{(5-6)}$. On the other hand, the United Kingdom Prospective Diabetic Study (UKPDS) has shown that intensive glycemic control can decrease the risk of visual loss in type 2 diabetes patients ${ }^{(7)}$.

The duration of DM is also a significant risk factor for the development of DR, after 20 years of DM $60 \%$ of type 2 DM patients have some degree of $\mathrm{DR}^{(8)}$. On the other hand, DR is rarely present in the first years after the diagnosis of DM. Based on such data, the American Academy of Ophthalmology (AAO) recommends that the first fundus examination in type 1 diabetics should be performed five years after the disease diagnosis ${ }^{(9)}$, as 
DR is rarely observed before that time period ${ }^{(10-11)}$. Nevertheless, subjects with type $2 \mathrm{DM}$ frequently are unable to accurately define when diabetes was first diagnosed and therefore DR may already be present at the time of diagno$\operatorname{sis}^{(12)}$. In such patients, fundus examination has been recommended to be performed soon after the diagnosis of DM is established $^{(9)}$.

Considering that DM may be present long before the disease is diagnosed and that endocrinologists tends to enforce stricter control of DM only after the ophthalmologic examination confirms the presence of $\mathrm{DR}^{(13)}$, we have hypothesized that the later the fundus examination is first performed, the greater the severity of DR would be. The purpose of this paper was therefore to investigate whether the time interval between type $2 \mathrm{DM}$ diagnosis and the first fundoscopic examination is related with the presence and the severity of DR observed.

\section{METHODS}

During a four-month period of time, 105 sequential patients with type 2 DM referred to the division of Ophthalmology of the University of São Paulo Medical School for ophthalmologic evaluation were asked to fill out a questionnaire and subsequently submitted to a complete fundoscopic examination. Questions were formulated to obtain information regarding the time elapsed since diabetes mellitus was first diagnosed; when was the first ophthalmoscopic examination performed; and whether laser treatment had already been performed. Patients were also asked whether they considered their DM under control, based on information obtained on the last medical evaluation. The quality of DM control (adequate or poor control) was based on patient's information based on results of previous laboratory examination. The study followed the principles of the Declaration of Helsinki. Approval from the Institutional Review Board Ethics Committee was obtained and all participants gave their informed consent.

Using a slit lamp and a 78 dioptries $V_{\text {olk }}{ }^{\circledR}$ lens, a retinal specialist performed the fundus examination of all patients after pupil dilatation with $10 \%$ phenylephrine and $1 \%$ tropicamide. DR was diagnosed and classified according to the severity scales recommended by the AAO. Each patient was classified as proliferative or non-proliferative disease ${ }^{(14)}$.

Data obtained from the patients in the questionnaire were compared with the recommendations of the $\mathrm{AAO}^{(4)}$. Patients submitted to a fundoscopic evaluation within one year of diagnosis of DM were considered to match the AAO recommendations (correct management while those that were referred more than one year after DM diagnosis were not correct).

The numerical variables were represented by mean value \pm standard deviation while categorical variables were described by absolute and relative frequencies. The chi-square test was employed for comparisons between groups. The correla- tion between the severity of DR and the time elapsed between the diagnosis of DM and the first fundoscopic examination was assessed using. A $p$ value of less than 0.05 was considered statistically significant.

\section{RESULTS}

Of the 105 subjects, $45.71 \%$ were male and $54.29 \%$ female. The mean standard deviation age was $63.5 \pm 10.0$ years (range, 41 - 86). Of 105 examined patients, 15 (14.28\%) had no signs of DR, 30 (28.57\%) showed mild non-proliferative DR, 18 (17.14\%) moderate non-proliferative DR, 5 (4.76\%) severe or very serious non-proliferative DR and 37 (35.24\%) proliferative DR. Sixty (57.14\%) of the 105 patients reported prior laser photocoagulation treatment.

Only 19 patients had their first fundoscopic examination within one year of DM diagnosis. The relationship between the time interval between DM diagnosis and the first FE with the classification of DR are listed on table 1. Patients with a greater time interval between DM diagnosis and the first FE showed a significant association with the severity of DR $(p<0.001)$ (Table 1).

Table 2 demonstrates the relationship between the time interval of the DM diagnosis and the correct time of the first FE. It was noted that the shorter the time interval of DM diagnosis, the earlier the examination was performed $(p<0.001)$.

After collecting data regarding the control of DM, these data were compared with the degree of DR classification. Among 105 patients, 67.62\% stated their DM was under control and $32.38 \%$ believed their DM had a poor control. Of the patients that indicated an adequate DM control, $21.12 \%$ had no signs of DR, $50.70 \%$ had non-proliferative DR and $28.18 \%$ had proliferative DR. All patients that referred poor DM control had DR on fundus examination; proliferative DR was present in $47.05 \%$ and non-proliferative in $52.95 \%$.

Table 3 compares the subjects that had already been treated with laser therapy and their report regarding the quality of DM control. Of the 60 patients with prior laser photocoagulation, $28(46.66 \%)$ mentioned unsuccessful DM control. There was a significant association between the severity of DR and the type of DM control. Patients with less severe retinopathy were those that reported adequate control of DM $(p<0.001)$.

\section{DISCUSSION}

Ophthalmologic complications of DM are very common and may be severe ${ }^{(15)}$, occurring in approximately $50 \%$ of the patients $^{(16)}$. In the current study, $80 \%$ of 105 examined patients revealed signs of DR, a much higher prevalence when compared with the study of Fernandez et al. $1998^{(17)}$ that found DR in $34.5 \%$ of 605 DM patients evaluated. This high proportion may be due to the fact that our sample was taken from a retinal specialist clinic. 
242 Relationship between diabetic retinopathy severity and the timespan between the endocrinopathy diagnosis and the first ophthalmic examination

\begin{tabular}{|c|c|c|c|}
\hline \multirow{3}{*}{$\begin{array}{l}\text { Classification } \\
\text { (considering the eye in a more advanced stage) } \\
\text { No signs of retinopathy }\end{array}$} & \multicolumn{3}{|c|}{ Time interval (months) } \\
\hline & 1 to 59 & 60 to 120 & $\geq 132$ \\
\hline & $11(73.33 \%)$ & $3(20.00 \%)$ & $1(6.67 \%)$ \\
\hline Mild non-proliferative diabetic retinopathy & $10(33.33 \%)$ & $19(63.33 \%)$ & $1(3.34 \%)$ \\
\hline Moderate non-proliferative diabetic retinopathy & $6(33.33 \%)$ & $9(50.00 \%)$ & $3(16.64 \%)$ \\
\hline Severe non-proliferative diabetic retinopathy & $1(20.00 \%)$ & $1(20.00 \%)$ & $3(60.00 \%)$ \\
\hline Proliferative diabetic retinopathy & $8(21.62 \%)$ & $7(18.92 \%)$ & $22(59.46 \%)$ \\
\hline
\end{tabular}

\begin{tabular}{|c|c|}
\hline $\begin{array}{l}\text { Time of diagnosis } \\
\text { (months) }\end{array}$ & $\begin{array}{c}\text { Correct time of first } \\
\text { fundoscopic eye examination } \\
\text { ( } 1 \text { years of diagnosis of DM) }\end{array}$ \\
\hline 1 a 72 & $\begin{array}{r}\text { Correct }=12(44.44 \%) \\
\text { Incorrect }=15(65.56 \%)\end{array}$ \\
\hline 73 a 180 & $\begin{aligned} \text { Correct } & =3(8.11 \%) \\
\text { Incorrect } & =34(91.89 \%)\end{aligned}$ \\
\hline$>180$ & $\begin{aligned} \text { Correct } & =4(9.75 \%) \\
\text { Incorrect } & =37(90.25 \%)\end{aligned}$ \\
\hline
\end{tabular}

\begin{tabular}{|lr|}
\hline Table 3. Relationship between laser therapy and disease control \\
Treated & Control of disease \\
Yes & Yes $=32(53.33 \%)$ \\
& No $=28(46.67 \%)$ \\
No & Yes $=39(86.66 \%)$ \\
& No $=6(13.34 \%)$ \\
\hline
\end{tabular}

The patients that did not follow the suggestions of the $\mathrm{AAO}^{(9)}$ regarding the first $\mathrm{FE}$ examination after the diagnosis of DM, showed greater severity of DR ( $p<0.001$, chi-square test). Since general practitioners and/or endocrinologists usually do not adopt stricter treatments for DM until the ophthalmologic examination confirms the presence of DR, as demonstrated in one of our previous work ${ }^{(13)}$ and since inadequate plasma glucose control is associated with an increase in DR severity ${ }^{(5-6)}$, not performing early fundoscopic examination in the disease not only causes a delay in the treatment of possible DR but also represents a lack of opportunity to stress adequate DM control for those with some signs of retinopathy.

This study suggests that the indication for the first FE (Table 2) in diabetic subjects has been improving over the years, since the results demonstrate that the shorter the diagnostic time interval of the DR, the earlier the first FE was accomplished. It is impressive that $90.25 \%$ of patients diagnosed with DM over 15 years ago underwent the first FE after 1 year of the diagnosis of their disease.

Table 3 illustrates that in spite of having undergone laser photocoagulation, $46.66 \%$ considered that their disease was still uncontrolled, demonstrating failure to comply with treatment. On the other hand, only $13.34 \%$ of those that had not been treated mentioned lack of control. Among those that mentioned control of DM, most of the patients $(21.12 \%)$ did not display signs of DR. All patients that reported poor DM control presented signs of DR. This suggests that the better the DM control, the lower the severity of DR, a fact already confirmed by the important UKPDS study ${ }^{(7)}$. These numbers have some limitation due to the absence of complementary test. The individuals evaluated in this study are far from the ideal ophthalmologic management advocated for type 2 diabetic patients, and only $15 \%$ are close to the recommendations ${ }^{(9)}$.

All this leads to considerations about various flaws in the follow-up care of these patients such as the inadequacy of information, their lack of interest regarding this illness, difficulty of access to public health care and even unawareness by general practitioners and endocrinologists about the correct indication of the FE for DM patients ${ }^{(17)}$.

Since laser therapy is a procedure that can cause ocular complication, it is extremely important that all possible factors of DM control be put into practice in order for this treatment to be deferred for as long as possible.

In conclusion, this study showed a statistically significant relationship between the time interval from the diagnosis of type $2 \mathrm{DM}$ and the first fundoscopic examination and the severity of DR. Clinicians and ophthalmologist should encourage type $2 \mathrm{DM}$ patients to undergo fundus examination soon after the diagnosis of DM is established in order to facilitate earlier detection and treatment of diabetic retinopathy.

\section{RESUMO}

Objetivo: Avaliar se o tempo de intervalo entre o diagnóstico do diabetes mellitus (DM) tipo 2 e o primeiro exame de fundo de olho está relacionado com a gravidade da retinopatia diabética (RD). Métodos: Inquérito realizado em 105 pacientes portadores de DM tipo 2 que foram referenciados para avaliação oftalmológica no Hospital das Clínicas da Faculdade de Medicina da Universidade de São Paulo. Resultados: Quanto à classificação da RD, dos 105 pacientes, 15 (14,28\%) não apresentavam sinais de RD e $90(85,72 \%)$ demonstraram presença de sinais de RD ao exame de fundo de olho. Somente $15,23 \%$ dos pacientes avaliados foram examinados no primeiro ano do diagnóstico de DM. Sessenta pacientes foram submetidos à laserterapia, 46,66\% relataram mal controle do DM. Quando examinados em até 5 anos de diagnóstico de DM, 36 (34,30\%), 
pacientes, $58,33 \%$ não apresentaram sinais ou demonstravam sinais de RD grau leve e $22,20 \%$ RD proliferativa. Trinta pacientes receberam exame oftalmológico superior a 11 anos do diagnóstico de DM, 21,62\% não apresentavam sinais de RD e 59,46\% classificados com RD proliferativa. Conclusão: Este estudo demonstrou significância estatística na relação entre o intervalo de tempo do diagnóstico do DM tipo 2 e o primeiro exame de fundo de olho com a gravidade de RD.

Descritores: Diabetes mellitus; Retinopatia diabética

\section{REFERENCES}

1. Klein R, Klein BE, Moss SE, Davis MD, DeMets DL. The Wisconsin Epidemiologic Study of Diabetic Retinopathy IV. Diabetic macular edema. Ophthalmology. 1984;91(12):1464-74.

2. Moss, SE, Klein, R, Klein BEK. The 14-year incidence of visual loss in a diabetic population. Ophthalmology. 1998;105(6):998-1003.

3. Brasil. Ministério da Saúde. Estatísticas [Internet]. [citado 2010 Jun 12]. RL:http://www.portalweb01.saude.gov.br/saude/aplicacoes/noticias/noticias detalhe.cfm?co seq noticia $=132$

4. Cohen RA, Hennekens CH, Christen WG, Krolewski A, Nathan DM, Peterson MJ,LaMotte F, Manson JE. Determinants of retinopathy progression in type 1 diabetes mellitus. Am J Med. 1999;107(1):45-51.

5. Klein R, Klein BE, Moss SE, Davis MD, DeMets DL.Glycosylated hemoglobin predicts the incidence and progression of diabetic retinopathy. JAMA. 1988;260(19):2864-71

6. Teuscher A, Schnell H, Wilson PWF. Incidence of diabetic retinopathy and relationship to baseline plasma glucose and blood pressure. Diabetes Care 1988; 11(3):246-51.
7. Tight blood pressure control and risk of macrovascular and microvascular complications in type 2 diabetes: UKPDS 38. UK Prospective Diabetes Study Group. BMJ. 1998;317(7160):703-13.

8. American Diabetes Association. Vital Statistics 1994 [Internet]. [cited 2010 June 26]. Available form: http://www.diabetes.org/diabetes-basics/diabetes-statistics

9. American Academy of Ophthalmology: Preferred practice pattern: diabetic Retinopathy. San Francisco: American Academy Ophthalmology;1993.

10. Klein R, Klein BEK, Moss SE, Davis MD, DeMets DL. The Wisconsin Epidemiologic Study of Diabetic Retinopathy II: Prevalence and risk of diabetic retinopathy when age of diagnosis is less than 30 years. Arch Ophthalmol. 1984; 102(4):520-6.

11. Klein R, Klein BEK, Moss SE, Davis MD, DeMets DL. The Wisconsin Epidemiologic Study of Diabetic Retinopathy IX: Four-year incidence and progression of diabetic retinopathy when age of diagnosis is less than 30 years. Arch Ophthalmol. 1989;107(2):237-43

12. Klein R, Klen BEK, Moss SE, Davis MD, DeMets DL. The Wisconsin Epidemiologic Study of Diabetic Retinopathy X: Four-year incidence and progression of diabetic retinopathy when age of diagnosis is less than 30 years. Arch Ophthalmol. 1989;107(2):244-9.

13. Preti RC, Saraiva FP, Trein Jr JA, Takahashi WY, Silva MER. How much information do medical practitioners and endocrinologists have about diabetic retinopathy? Clinics 2007;62(3):273-8.

14. Wilkinson CP. Ferris FL $3^{\text {rd }}$. Klein RE. Lee PP. Agardh CD. Davis M. Dills D. Kampik A. Pararajasegaram R. Verdaguer JT. Proposed international clinical diabetic retinopathy and diabetic macular edema disease severity scales. Global Diabetic Retinopathy Project Group. Ophthalmology. 2003;110(9):1677-82

15. Ministério da Saúde do Brasil. Sociedade Brasileira de Diabetes. Diabete Melito. Guia Básico Para Diagnóstico e Tratamento. Programa Harvard/Joslin/SBD. Brasília (DF): Ministério da Saúde;1996. p.5, 7 ,57.

16. Associação Latinoamericana de Diabete. Consenso sobre prevenção, controle e tratamento do DMNID da ALAD. [Apresentado no $9^{\circ}$ Congresso Latinoamericano de Diabete. Foz do Iguaçu (SP); 1996].

17. Fernandez, Maria Luiza M. P; Moura, Cintia A. A; Jorge, Paulo T. Estudo de prevalência de retinopatia diabética no ambulatório da Universidade Federal de Uberlândia. Arq Bras Endocrinol Metab. 1998,42(5):368-73. 